\title{
HEAD CIRCUMFERENCE OF INFANTS RELATED TO BODY WEIGHT
}

\author{
BY \\ R. S. ILLINGWORTH and W. LUTZ \\ From the Department of Child Health, and the Department of Statistics, the University of Sheffield
}

(RECEIVED FOR PUBLICATION FEBRUARY 24, 1965)

The measurement of the maximum circumference of the head is a part of the routine physical examination of any baby, just as much as examination of the heart, chest, and abdomen, as examination of the hips for subluxation, of the urine for phenylpyruvic acid, and of the hearing after the age of 3 or 4 months, The importance of measuring the head circumference lies partly in the early detection of hydrocephalus, which is now amenable to surgical procedures, and partly in the early diagnosis of mental subnormality. When there are indications for a careful developmental assessment, measurement of the maximum head circumference is a vital part of the examination.

Though the maximum head circumference is of great importance in developmental and neurological assessment, there are several difficulties in its interpretation. A large head may be merely a familial feature. It is rarely due to megalencephaly, and still more rarely to hydranencephaly. The diagnosis of the obvious cause, hydrocephalus, is normally supported by other clinical signs, such as a bulging fontanelle or undue separation of the sutures. In the very young baby with a spina bifida, air studies may demonstrate a fairly considerable degree of hydrocephalus before its presence is revealed by an excessive head size or excessive increase in its size (Lorber, 1961).

A small head is not strictly synonymous with microcephaly. It may, for instance, be a familial feature. A true microcephalic head is characterized not only by the small head circumference, but by its shape, and in particular by the excessive tapering off toward the vertex.

Microcephaly is usual in children suffering from mental subnormality (unless there be hydrocephalus, megalencephaly, or hydranencephaly), and if a mentally subnormal child has developed normally during the early months, the head will by then have attained much of its eventual size. By the age of 9 months the brain has reached half its adult size, and by the age of 2 years, three-quarters its adult size. To put it another way, if mental subnormality dates from birth or before birth, the head is usually small. The later in the first year at which the mental subnormality develops, the less will be the evidence of microcephaly. If it develops after the first year there will be no significant evidence of microcephaly.

A broad head (brachycephaly), with a flat occiput, may have an average head circumference, but it is nevertheless commonly associated with mental subnormality. The head in generalized craniostenosis may be unduly small, but craniostenosis is distinguished from microcephaly by palpation of the sutures and by radiological examination.

Serial measurements are more important than isolated measurements. A changing relationship between the head circumference and its placing on the percentile head chart may well indicate the development of hydrocephalus or microcephaly (Fig. 1). On the other hand, a placing above or below the upper or lower percentile respectively will be seen to be normal when serial measurements indicate that the position in relation to the percentile is not changing (Fig. 2).

A minor difficulty in interpretation of the head circumference lies in the fact that the younger the baby (or foetus) the larger the head size in relation to the size of the rest of the baby.

A major difficulty is the obvious fact that at any given age a large baby is likely to have a larger head than a small baby, and vice versa. It is necessary, therefore, to relate the size of the head to the size of the baby-and a convenient index of the size of the baby is his weight. Up to the present, we have plotted the head circumference on a chart which gives the 10th, 50th, and 90th percentiles, and his weight against a weight chart which gives the same percentiles for the relevant sex at the age in question. One can then determine whether his head size corresponds with (i.e. occupies the same relative percentile position as) his weight. This method 


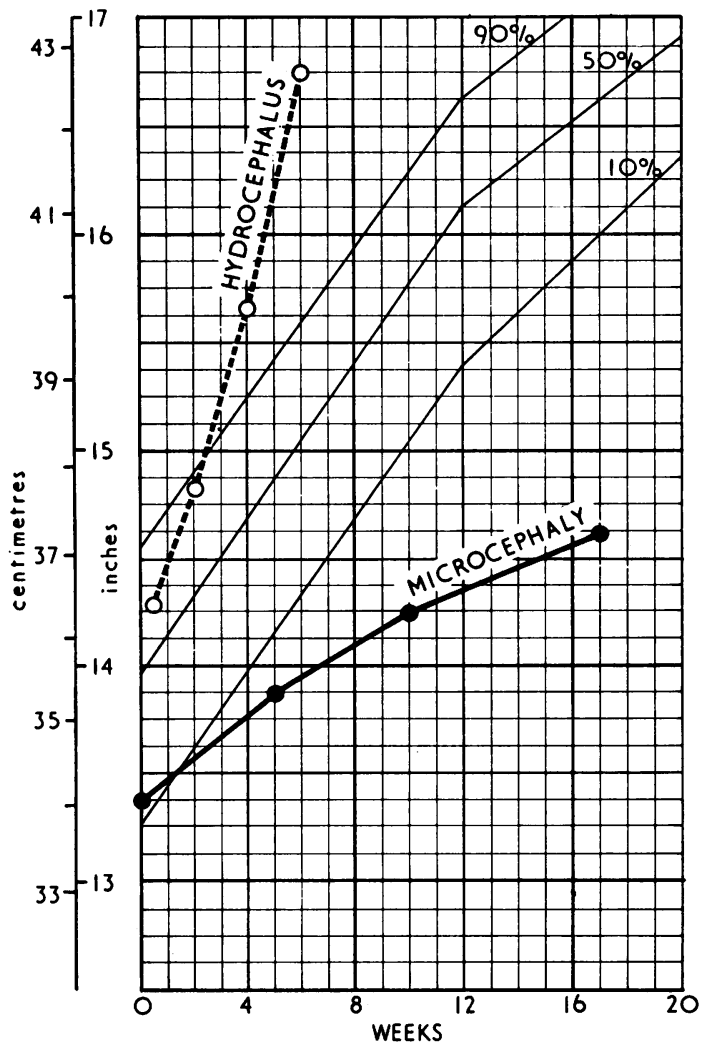

Fig. 1.-Head circumference: serial measurements in a case of hydrocephalus and a case of microcephaly.

involves the use of two charts for each child. Our present study was intended to provide a more accurate method of relating the head size to the weight, using a single graph for each child.

\section{Material and Methods}

During a joint obstetrical and paediatric study made with a different object, we kept a record of certain physical measurements including the child's weight and maximum head circumference. The children were seen at birth, and followed up as nearly as possible at the ages of 6 weeks, 6 months, and 10 months. Those ages were chosen because it was felt that they were the best for developmental assessment. The total number of children for whom we have the necessary measurements is shown in the statistical addendum (Table A).

The nude weight was recorded. The maximum head circumference was measured by a non-elastic soft tape which was checked for accuracy at frequent intervals. Infants who were suspected on developmental testing of being mentally subnormal, or of having hydrocephalus, were excluded from this investigation. Table 1 gives the average head circumference and weight of the boys and

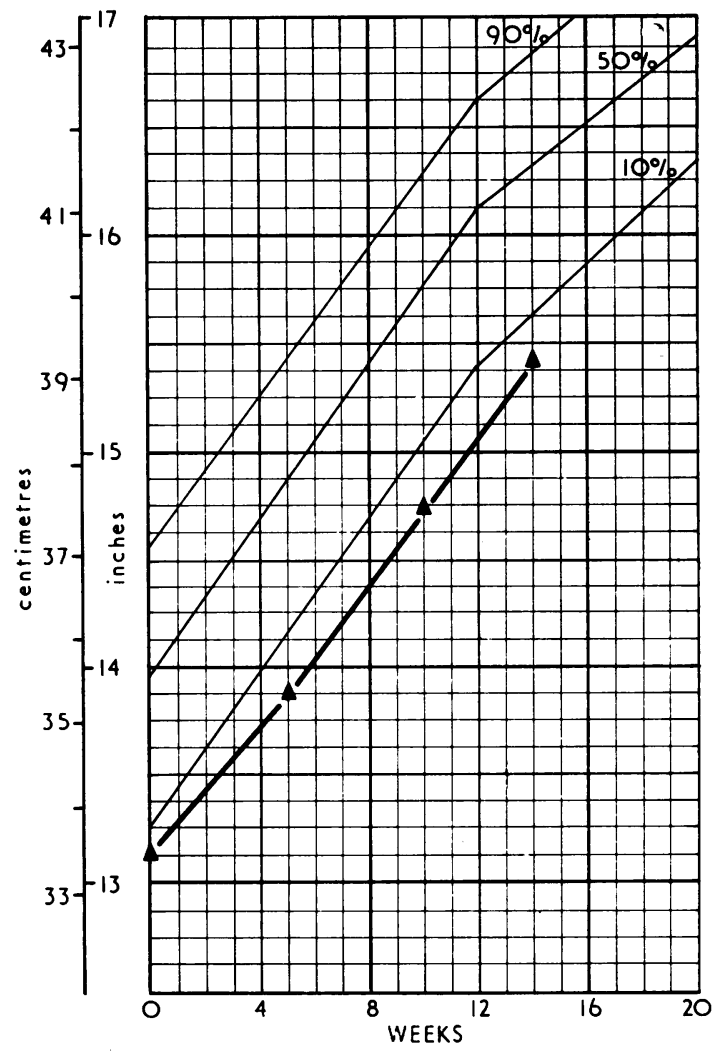

FIG. 2.-Head circumference in a normal small child; serial measurements indicate normal rate of head growth.

girls studied in this investigation. The figures indicate that there is a direct relationship between body weight and head circumference.

\section{Results}

We had hoped to obtain one graph for each sex, covering the four age periods, but it was found that the data available would not permit this. Consequently we have prepared eight graphs, four for each sex, covering the periods of birth, 6 weeks, 6 months, and 10 months (Figs. 3 and 4). From these graphs it is immediately possible to determine the expected head circumference for a child of given sex, age, and weight.

It can be seen from the graphs that the expected head circumference can be calculated with reasonable accuracy by subtracting (or adding) the following measurements from (or to) the head circumference for each pound above (or below) the average weight (Table 2).

We emphasize that the head circumference of most children will not coincide with these average values. 
TABLE 1

HEAD CIRCUMFERENCE RELATED TO WEIGHT AT DIFFERENT AGES

\begin{tabular}{|c|c|c|c|c|c|c|c|c|c|c|c|}
\hline & & \multicolumn{3}{|c|}{ Boys } & \multicolumn{3}{|c|}{ Girls } & \multicolumn{4}{|c|}{ Weight } \\
\hline & & \multicolumn{2}{|c|}{$\begin{array}{l}\text { Average Head } \\
\text { Circumference }\end{array}$} & \multirow{2}{*}{$\begin{array}{c}\text { Regression } \\
\text { Coefficient } \\
\text { Head } \\
\text { Circumfer- } \\
\text { ence on } \\
\text { Weight }\end{array}$} & \multicolumn{2}{|c|}{$\begin{array}{l}\text { Average Head } \\
\text { Circumference }\end{array}$} & \multirow{2}{*}{$\begin{array}{c}\text { Regression } \\
\text { Coefficient } \\
\text { Head } \\
\text { Circumfer- } \\
\text { ence on } \\
\text { Weight }\end{array}$} & \multicolumn{2}{|c|}{ Boys } & \multicolumn{2}{|c|}{ Girls } \\
\hline & & Inch & $\mathrm{Cm}$. & & Inch & $\mathrm{Cm}$. & & lb. oz. & g. & lb. oz. & g. \\
\hline $\begin{array}{l}\text { Birth ... } \\
6 \text { weeks } \\
6 \text { months } \\
10 \text { months }\end{array}$ & $\begin{array}{c}\cdots \\
\cdots \\
\cdots\end{array}$ & $\begin{array}{l}13 \cdot 7 \\
15 \cdot 3 \\
17 \cdot 5 \\
18 \cdot 4\end{array}$ & $\begin{array}{l}34 \cdot 8 \\
38 \cdot 9 \\
44 \cdot 4 \\
46 \cdot 7\end{array}$ & $\begin{array}{l}0 \cdot 343 \\
0 \cdot 235 \\
0 \cdot 122 \\
0 \cdot 114\end{array}$ & $\begin{array}{l}13 \cdot 8 \\
14 \cdot 9 \\
17 \cdot 0 \\
17 \cdot 9\end{array}$ & $\begin{array}{l}35 \cdot 0 \\
37 \cdot 8 \\
43 \cdot 2 \\
45 \cdot 5\end{array}$ & $\begin{array}{l}0.231 \\
0.262 \\
0.124 \\
0.099\end{array}$ & $\begin{array}{cc}7 & 5 \frac{1}{2} \\
10 & 13 \\
18 & 12 \frac{1}{2} \\
22 & 2 \frac{1}{2}\end{array}$ & $\begin{array}{r}3,180 \\
4,860 \\
8,520 \\
10,460\end{array}$ & $\begin{array}{cc}7 & 5 \frac{1}{4} \\
10 & 0 \\
17 & 7 \frac{1}{4} \\
20 & 10 \frac{1}{2}\end{array}$ & $\begin{array}{l}3,180 \\
4,500 \\
7,840 \\
9,380\end{array}$ \\
\hline
\end{tabular}

There are considerable normal variations, and it is essential to take into account the $95 \%$ confidence limits, and all the relevant clinical features mentioned.

TABLE 2

CALCULATION OF EXPECTED HEAD CIRCUMFERENCE FROM AGE AND WEIGHT*

\begin{tabular}{|c|c|c|c|c|c|}
\hline & & \multicolumn{2}{|c|}{ Boys } & \multicolumn{2}{|c|}{ Girls } \\
\hline & & Inch & $\mathrm{Cm}$. & Inch & $\mathrm{Cm}$. \\
\hline $\begin{array}{l}\text { Birth } \\
6 \text { weeks } \ldots \\
6 \text { months .. } \\
10 \text { months }\end{array}$ & $\begin{array}{l}\ldots \\
\cdots \\
\cdots\end{array}$ & $\begin{array}{l}0 \cdot 3 \\
0 \cdot 25 \\
0 \cdot 125 \\
0 \cdot 1\end{array}$ & $\begin{array}{l}0.8 \\
0.6 \\
0 \cdot 3 \\
0.3\end{array}$ & $\begin{array}{l}0 \cdot 25 \\
0 \cdot 25 \\
0 \cdot 125 \\
0 \cdot 1\end{array}$ & $\begin{array}{l}0.6 \\
0.6 \\
0.3 \\
0.3\end{array}$ \\
\hline
\end{tabular}

* The figures show the amount to be added to or subtracted from the head circumference for each $l b$. above or below the average weight.
There is bound to be some degree of error in head and weight measurements. In practice, allowance for the influence of body weight will be made in older infants of over 6 months, only in extreme cases of overweight or underweight. It is important to note that a sudden loss of weight, such as may occur with acute dehydration, will disturb the relation between head circumference and weight. A sudden increase of weight will normally be accompanied by a corresponding increase in head size. At first sight this might lead the unwary, relying on a head chart alone, to make the erroneous diagnosis of hydrocephalus.

The relationship of head size to weight in grossly underweight children with the 'failure to thrive' picture, is still uncertain. Dean (1965) found that
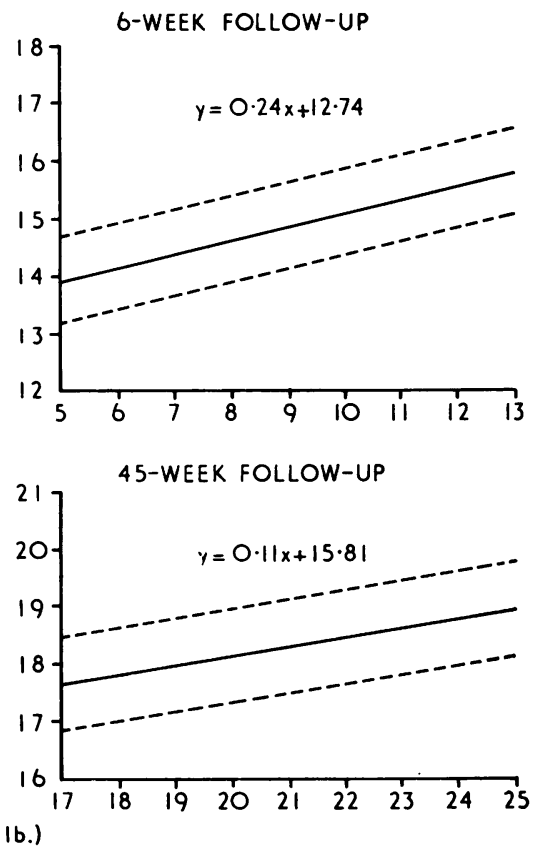

FIG. 3.-Relationship of head circumference to weight (boys). 


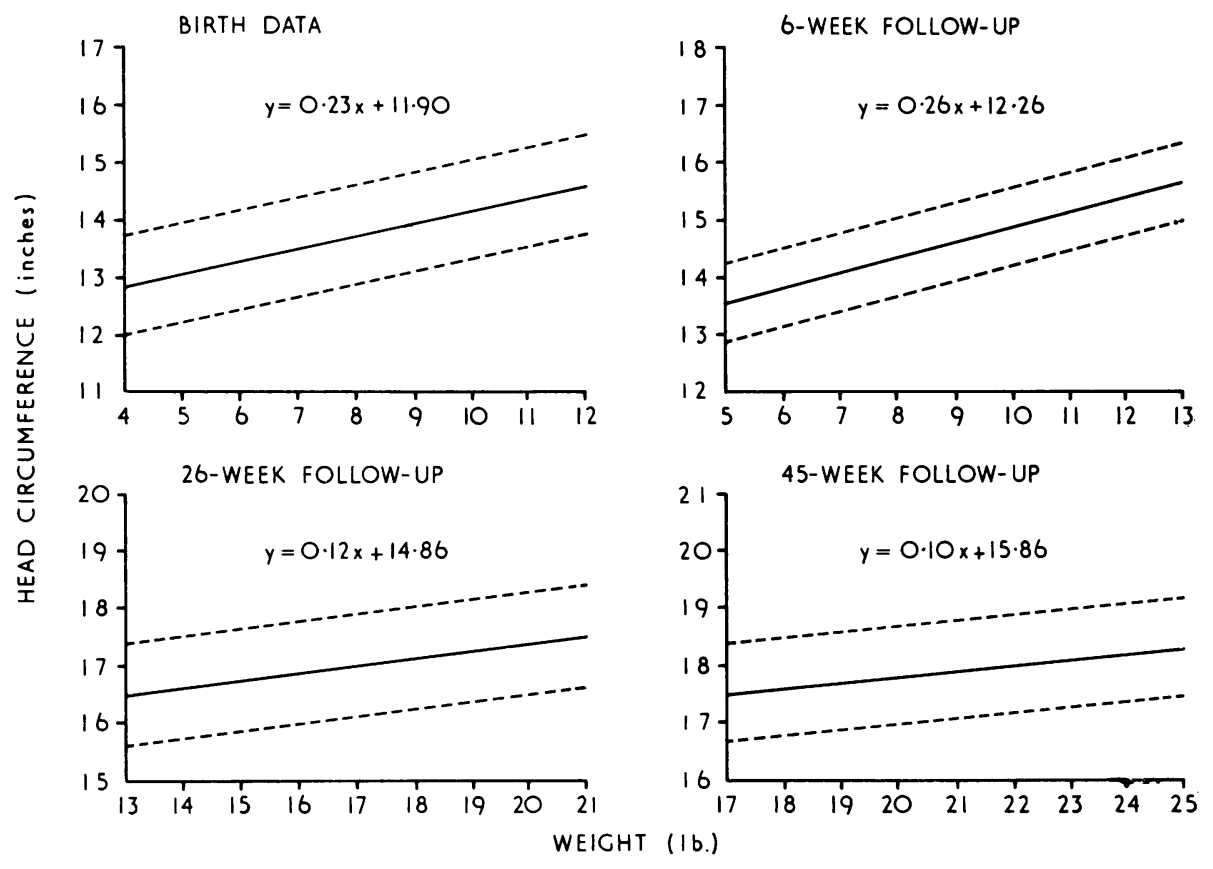

FIG. 4.-Relationship of head circumference to weight (girls).

the relationship between the circumference of the head and that of the chest was useful in assessing children with severe malnutrition, such as kwashiorkor. Whereas the circumference of the head is normally greater than that of the chest until the age of 6 months, that of the chest is normally greater after that age. Dean found that in malnutrition the measurement affected least was the head circumference, and that the head was nearly always larger than it should be in relation to the size of the body. In malnourished children the extent of the difference between the circumference of the head and the thorax was related in a statistically significant way.

\section{Discussion}

Too much must not be read into an unusual head size, but in conjunction with other clinical features, it is of the utmost importance in developmental assessment. Thus, if a child is developmentally retarded, and the head circumference is found to be low in relation to his weight, one will be very suspicious that he may prove to be mentally subnormal. If, on the other hand, the child is developmentally retarded and yet the head circumference corresponds well with the weight, the child may be an example of delayed maturation, and later prove to be normal. In doubtful cases serial measurements can throw a great deal of light on the problem.

\section{Summary}

The measurement of the maximum head circumference must be part of the routine examination of any baby.

It must be related to the size of the baby, and the weight is a good index of this.

Graphs have been constructed in which the head circumference is related to the size of the baby. A table, which enables a rough correction to be made in order to relate the head size to the weight, is given.

Difficulties in interpreting the results are discussed.

We wish to thank the Spastics Society for support in the joint obstetrical and paediatric study, from which the figures were obtained for this investigation.

\section{REFERENCES}

Dean, R F. A. (1965). Effects of malnutrition, especially of slight degree, on the growth of young children. Courrier, 15, 73.

Lorber, J. (1961). Systematic ventriculographic studies in infants born with meningomyelocele and encephalocele: the incidence and development of hydrocephalus. Arch. Dis. Childh., 36, 381.

\section{Statistical Addendum}

The data for boys and girls were analysed separately and the subsequent results showed that the boys had a slightly larger head circumference at all ages after birth. We realized that a linear regression over the whole period of 45 weeks was unlikely to be realistic. On the other 
TABLE A

\begin{tabular}{|c|c|c|c|c|c|c|c|c|c|c|}
\hline & & \multicolumn{2}{|c|}{ No. of Cases } & \multicolumn{2}{|c|}{ Mean Age (wk.) } & \multicolumn{2}{|c|}{$\begin{array}{c}\text { Standard Deviation } \\
\text { of Age }\end{array}$} & \multirow[t]{2}{*}{$\begin{array}{l}\text { Range of } \\
\text { Ages (wk.) } \\
\text { (sexes } \\
\text { combined) }\end{array}$} & \multicolumn{2}{|c|}{$\begin{array}{c}\text { Regression Coefficient } \\
\text { Head Circumference } \\
\text { on Weight }\end{array}$} \\
\hline & & Boys & Girls & Boys & Girls & Boys & Girls & & Boys & Girls \\
\hline $\begin{array}{l}\text { Birth } \\
\text { Ist follow-up } \\
\text { 2nd follow-up } \\
\text { 3rd follow-up }\end{array}$ & $\begin{array}{l}\cdots \\
\cdots \\
\cdots \\
\cdots\end{array}$ & $\begin{array}{l}397 \\
362 \\
353 \\
356\end{array}$ & $\begin{array}{l}311 \\
307 \\
295 \\
312\end{array}$ & $\begin{array}{r}\overline{6 \cdot 7} \\
26 \cdot 7 \\
44 \cdot 6\end{array}$ & $\begin{array}{r}\overline{6 \cdot 7} \\
26 \cdot 8 \\
44 \cdot 8\end{array}$ & $\begin{array}{l}\overline{1 \cdot 27} \\
1 \cdot 50 \\
2 \cdot 02\end{array}$ & $\begin{array}{l}\overline{1 \cdot 28} \\
2 \cdot 06 \\
2 \cdot 52\end{array}$ & $\begin{array}{r}\overline{4-15} \\
21-36 \\
35-57\end{array}$ & $\begin{array}{l}0 \cdot 343 \\
0 \cdot 235 \\
0 \cdot 122 \\
0 \cdot 114\end{array}$ & $\begin{array}{l}0 \cdot 231 \\
0 \cdot 262 \\
0 \cdot 124 \\
0 \cdot 099\end{array}$ \\
\hline
\end{tabular}

hand, fitting a curve to data concentrated at 4 points only $(0,6,26$, and 45 weeks) was not advisable.

Hence each of the four stages, birth, and the follow-up studies at 6,26 , and 45 weeks, was treated separately.

A comparison of the linear regression lines of head circumference on gestation and birth weight, with the regression line on birth weight only (both sexes treated separately), clearly showed that gestation did not reduce the sum of squares about the regression curve to any worth-while degree. Thus gestation, as a predictor of head circumference, was unsatisfactory for the birth data and would obviously be of even less value at older ages.

Mothers were requested to bring their children in for examination at the three stated ages. Not all were able to comply, resulting in a varying number of cases at the different follow-ups. Moreover, mothers were not always able to adhere precisely to the times requested, resulting in a variation of age at each of the follow-up periods.

Table A shows the extent of these variations in numbers and age.

Analysis showed that the variable 'age' at each followup study did not reduce the sum of squares about the regression line by more than a minute fraction. Since gestation as a predictor had already been eliminated, we finally used the regression line of head circumference on weight only at each of the four age stages, and for each sex.

It is not claimed that there is no relationship between age and head circumference. In fact, there must exist, at least in the first year, a fairly strong relationship between head circumference on the one hand with age and weight on the other. However, the limited age variation at each single follow-up study added little to the ability to predict head circumference. The regression studies, therefore, seem applicable to children whose ages vary a few weeks either side of the mean ages $6 \frac{1}{2}, 26$, and 45 weeks.

Cases of hydrocephalus and microcephalus (not included in the series) showed their head circumferences to lie well outside the $95 \%$ confidence belts as shown on the graphs, in nearly all instances.

Table A also shows the regression coefficients of head circumference on weight at the four periods studied. The regression coefficient 0.343 for boys and 0.231 for girls at birth was significantly different at the $95 \%$ level. At later ages the regression coefficients for boys and girls were not significantly different. The decline in the regression coefficients with age clearly indicates that weight alone becomes an increasingly poor predictor of head circumference with age, at least on its own. For older children a combination of several variables will have to be considered if a good predictor of head circumference is desired. 